\title{
The CCG-domain-containing subunit SdhE of succinate:quinone oxidoreductase from Sulfolobus solfataricus P2 binds a $[4 \mathrm{Fe}-4 \mathrm{~S}]$ cluster
}

\author{
Nils Hamann · Eckhard Bill $\cdot$ Jacob E. Shokes • \\ Robert A. Scott · Marina Bennati · Reiner Hedderich
}

Received: 8 July 2008/Accepted: 3 December 2008/Published online: 16 December 2008

(C) The Author(s) 2008. This article is published with open access at Springerlink.com

\begin{abstract}
In type E succinate:quinone reductase (SQR), subunit $\mathrm{SdhE}$ (formerly $\mathrm{SdhC}$ ) is thought to function as monotopic membrane anchor of the enzyme. SdhE contains two copies of a cysteine-rich sequence motif $\left(\mathrm{CX}_{n} \mathrm{CCGX}_{m} \mathrm{CXXC}\right)$, designated as the CCG domain in the Pfam database and conserved in many proteins. On the basis of the spectroscopic characterization of heterologously produced SdhE from Sulfolobus tokodaii, the
\end{abstract}

Electronic supplementary material The online version of this article (doi:10.1007/s00775-008-0462-8) contains supplementary material, which is available to authorized users.

N. Hamann $\cdot$ R. Hedderich $(\square)$

Max Planck Institute for Terrestrial Microbiology,

Karl-von-Frisch-Strasse,

35043 Marburg, Germany

e-mail: hedderic@mpi-marburg.mpg.de

Present Address:

N. Hamann

Richter-Helm BioLogics,

Habichthorst 30, 22459

Hamburg, Germany

E. Bill

Max Planck Institute for Bioinorganic Chemistry,

Stiftstrasse 34-36,

45470 Mülheim/Ruhr, Germany

J. E. Shokes - R. A. Scott

Department of Chemistry,

University of Georgia,

Athens, GA 30602-2556, USA

\section{Bennati}

Max Planck Institute for Biophysical Chemistry,

Am Fassberg 11,

37077 Göttingen, Germany protein was proposed in a previous study to contain a labile [2Fe-2S] cluster ligated by cysteine residues of the CCG domains. Using UV/vis, electron paramagnetic resonance (EPR), ${ }^{57} \mathrm{Fe}$ electron-nuclear double resonance (ENDOR) and Mössbauer spectroscopies, we show that after an in vitro cluster reconstitution, SdhE from $S$. solfataricus $\mathrm{P} 2$ contains a $[4 \mathrm{Fe}-4 \mathrm{~S}]$ cluster in reduced $(2+)$ and oxidized $(3+)$ states. The reduced form of the $[4 \mathrm{Fe}-4 \mathrm{~S}]^{2+}$ cluster is diamagnetic. The individual iron sites of the reduced cluster are noticeably heterogeneous and show partial valence localization, which is particularly strong for one unique ferrous site. In contrast, the paramagnetic form of the cluster exhibits a characteristic rhombic EPR signal with $g_{z y x}=2.015,2.008$, and 1.947. This EPR signal is reminiscent of a signal observed previously in intact SQR from $S$. tokodaii with $g_{z y x}=2.016,2.00$, and 1.957. In addition, zinc K-edge $\mathrm{X}$-ray absorption spectroscopy indicated the presence of an isolated zinc site with an $\mathrm{S}_{3}(\mathrm{O} / \mathrm{N})_{1}$ coordination in reconstituted $\mathrm{SdhE}$. Since cysteine residues in $\mathrm{SdhE}$ are restricted to the two CCG domains, we conclude that these domains provide the ligands to both the iron-sulfur cluster and the zinc site.

Keywords Succinate dehydrogenase - Complex II . ENDOR spectroscopy · Mössbauer spectroscopy · Monotopic membrane anchor $\cdot$ CCG domain

$\begin{array}{ll}\text { Abbreviations } \\ \text { DTT } & \text { Dithiothreitol } \\ \text { ENDOR } & \text { Electron-nuclear double resonance } \\ \text { EPR } & \text { Electron paramagnetic resonance } \\ \text { HDR } & \text { Heterodisulfide reductase } \\ \text { NEM-FTR } & \text { Alkylated ferredoxin:thioredoxin reductase } \\ \text { QFR } & \text { Quinol:fumarate reductase } \\ \text { SQOR } & \text { Succinate:quinone oxidoreductase }\end{array}$


SQR Succinate:quinone reductase

Tris Tris(hydroxymethyl)aminomethane

XAS X-ray absorption spectroscopy

\section{Introduction}

Succinate:quinone oxidoreductases (SQORs; EC 1.3.5.1) have been ubiquitously detected in organisms from the three domains of life. These enzymes couple the twoelectron oxidation of succinate to fumarate with the twoelectron reduction of quinone to quinol. Depending on the direction of the reaction catalyzed in vivo, SQORs can be classified as either succinate:quinone reductases (SQRs) or quinol:fumarate reductases (QFRs) [1]. SQR is both a citric acid cycle enzyme and a component of the respiratory chain (complex II) in aerobic metabolism, whereas QFR participates in anaerobic respiration with fumarate as a terminal electron acceptor [2].

SQRs and QFRs from archaea, bacteria, and mitochondria of eukaryotes are membrane-anchored complexes with a hydrophilic domain extending into the cytoplasm or the mitochondrial matrix, respectively. The membrane attachment domains were previously used to classify SQOR $[1,3]$. Recently the type A-D classification was extended to the whole enzyme and a novel subfamily was included as type $\mathrm{E}[4,5]$. The hydrophilic domain generally consists of two subunits (SdhA and SdhB), that are closely related in all types of SQOR (Fig. 1). The succinate oxidizing subunit SdhA is a flavoprotein, harboring a covalently bound FAD. The iron-sulfur protein SdhB functions as an electron transfer module, containing one $[2 \mathrm{Fe}-2 \mathrm{~S}]^{2+/+}$ (S1), one $[4 \mathrm{Fe}-4 \mathrm{~S}]^{2+/+}(\mathrm{S} 2)$, and one $[3 \mathrm{Fe}-4 \mathrm{~S}]^{+/ 0}$ (type AD) cluster or a second $[4 \mathrm{Fe}-4 \mathrm{~S}]^{2+/+}$ (type E) cluster (S3) [6]. The membrane anchor of types A and B SQOR binds two heme molecules, that of type $\mathrm{C}$ binds one heme group, and that of type D has no heme group [4]. In contrast, type E SQORs, e.g., the enzymes from Sulfolobus acidocaldarius, S. tokodaii, and Acidianus ambivalens [7-9], lack the typical membrane anchoring subunit(s) with transmembrane spanning helices as found in the other four types of SQOR (Fig. 1b). The proposed membrane anchoring domain of type E SQOR consists of two polypeptides which lack transmembrane spanning helices and are not sequence-related to SdhC and SdhD of type A-D enzymes. For this reason these subunits were recently renamed SdhE and $\mathrm{SdhF}$, respectively [5]. It has been suggested that SdhE (and probably also $\mathrm{SdhF}$ ) functions as a monotopic membrane anchor of the enzyme and harbors the quinone (e.g., caldariella quinone) binding site [9].

SdhE contains two cysteine-rich sequence motifs $\left(\mathrm{CX}_{n} \mathrm{CCGX}_{m} \mathrm{CXXC}\right)$ designated as the CCG domain in the Pfam protein families database (accession number PF02754). The highly conserved tandem cysteine motif (CC) which is
Fig. 1 The domain architecture of type E succinate:quinone reductase (SQR) in comparison with those of type A-D SQR, thiol:fumarate reductase, and two different types of heterodisulfide reductase. Conserved domains or subunits are indicated by the same color. $Q$ ubiqinone or menaquinone, $C Q$ caldariella quinone, $M P$ methanophenazine, $\mathrm{CoM}-\mathrm{SH}$ coenzyme M, CoB-SH coenzyme B, CoM-S-S-CoB heterodisulfide of coenzyme $\mathrm{M}$ and coenzyme B

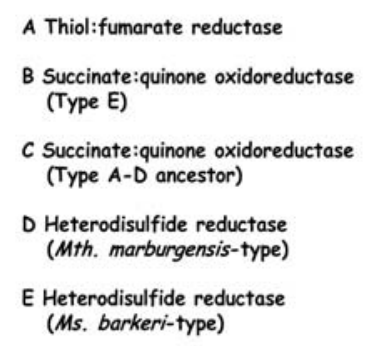

A

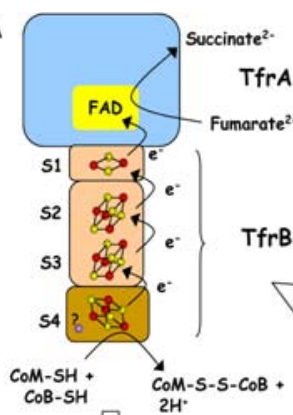

E
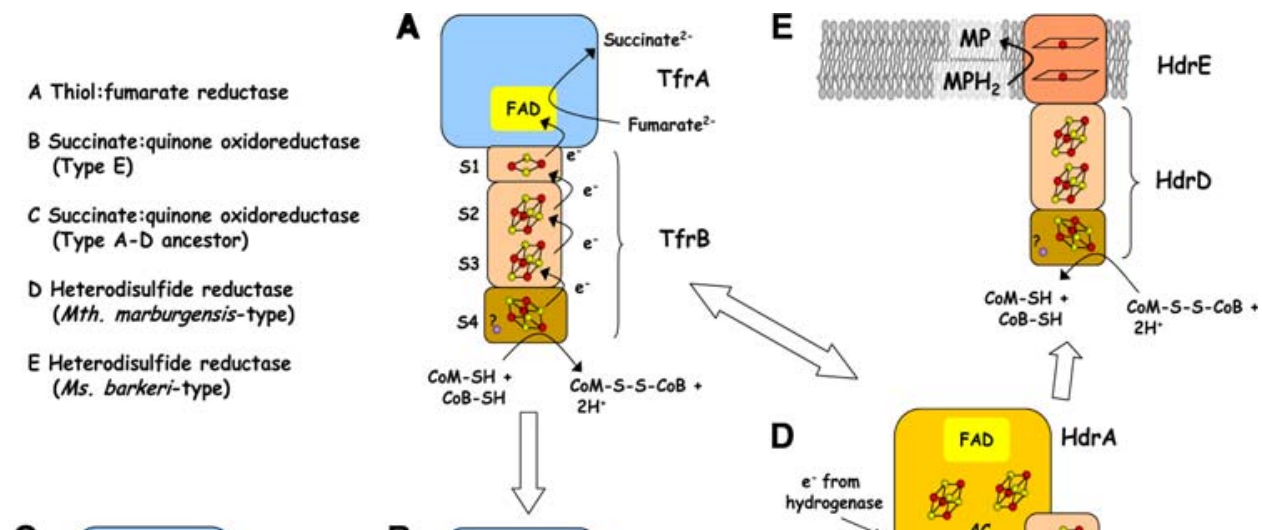

C

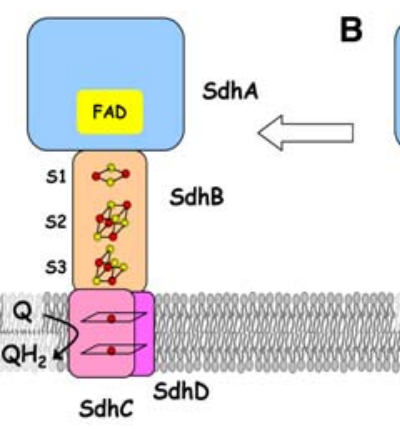

B
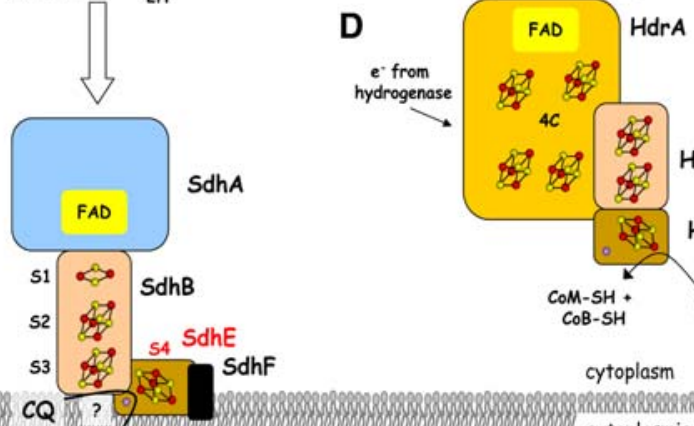

$\mathrm{CQH}_{2}$
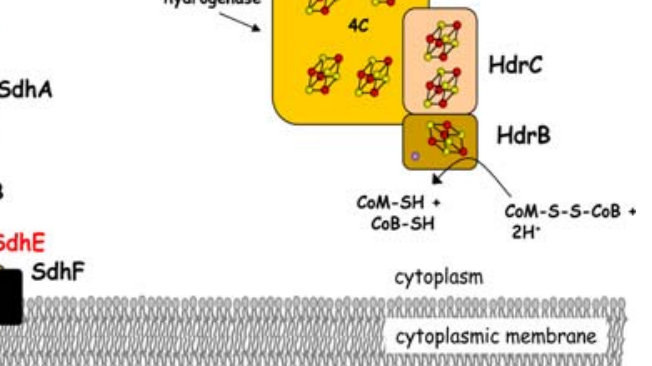

cytoplasm

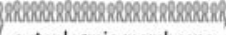
cytoplasmic membrane $\mathrm{SdhC}$ 
followed by a glycine residue in many sequences was used as the eponym for the CCG domain [10]. A database search indicates that the CCG domain is conserved in a large number of proteins belonging to the archaeal and bacterial domains [11]. This protein family currently has 1,871 members. In most of these proteins the CCG domain is present in two copies, but in some proteins the N-terminal CCG domain is degenerated and conserved cysteine residues are replaced by other amino acid residues. The function of the CCG domain was addressed in a recent study using subunit HdrB of heterodisulfide reductase (HDR) from Methanothermobacter marburgensis [12] (Fig. 1). As for SdhE, HdrB contains two fully conserved CCG domains. The overall sequence identity between HdrB and SdhE is, however, only $31 \%$. HdrB heterologously produced in Escherichia coli was found to contain an iron-sulfur cluster after an in vitro cluster reconstitution step. With use of sitedirected mutagenesis, cysteine residues of the C-terminal CCG domain were identified as cluster ligands. In its oxidized state this cluster exhibited electron paramagnetic resonance (EPR) spectroscopic properties reminiscent of CoM-HDR, a paramagnetic reaction intermediate of HDR. ${ }^{57} \mathrm{Fe}$ electron-nuclear double resonance (ENDOR) spectroscopy revealed that this paramagnetic species is a $[4 \mathrm{Fe}-$ $4 \mathrm{~S}$ ] cluster with an electronic structure very similar to that of CoM-HDR [12]. Zinc K-edge X-ray absorption spectroscopy (XAS) investigations in addition demonstrated the presence of an isolated zinc site in HdrB as well as in native HDR with a coordination environment that includes three sulfurs and one nitrogen/oxygen.

The binding of metal centers to subunit SdhE of SQR from $S$. tokodaii heterologously produced in $E$. coli was also addressed in a previous study [13, 14]. Zinc K-edge XAS investigations demonstrated the presence of an isolated zinc site in SdhE with a coordination environment that includes three sulfurs and one nitrogen (or oxygen). These data are consistent with the data obtained for HdrB. The further analysis of the purified protein by visible/ near-UV absorption and resonance Raman spectroscopies suggested the presence of a $[2 \mathrm{Fe}-2 \mathrm{~S}]$ cluster as the dominant species in SdhE. The absorbance was irreversibly lost after incubation with sodium dithionite, indicating cluster breakdown upon reduction. The as-isolated protein also exhibited a rhombic EPR signal with $g_{z y x}=2.015,2.00$, and 1.947 at substoichiometric amounts. This resonance was attributed to an unusual [2Fe-2S] cluster in the reduced state [13]. These data are in strong contrast to the data obtained for HdrB. We therefore reinvestigated the cluster type in SdhE in this study. Using SdhE from S. solfataricus P2 heterologously produced in $E$. coli, we show that after in vitro cluster reconstitution the protein contains a $[4 \mathrm{Fe}-4 \mathrm{~S}]$ cluster. We provide detailed information on the spectroscopic properties of this cluster and discuss its possible role in type E SQR.

\section{Materials and methods}

Chemicals were from Merck (Darmstadt, Germany) or Sigma (Taufkirchen, Germany). Caldariella quinone was a gift from Christian Schmidt, University of Lübeck, Germany.

\section{Expression of SdhE in E. coli}

The $s d h E$ gene from $S$. solfataricus P2 (GeneBank accession number AE006837; locus SSO2358; currently annotated as $s d h C$ ) was amplified by PCR using genomic DNA as a template and the oligonucleotides 5'-CATATG AAAATAGCTTATTATCCTGGATG- $3^{\prime}$ and $5^{\prime}$ - $\overline{\text { GCGGCC }}$ GCTCATATCACTCCCTTACTTCGTAGTAC- $3^{\prime}$ as primers. After gel extraction, the PCR product obtained was cloned in $\mathrm{pCR}^{\circledR}$ 2.1-TOPO (Invitrogen, Karlsruhe, Germany). The NdeI and Not I restriction sites thus generated were used to subclone the $s d h E$ gene into pET-24b(+) (Novagen, Darmstadt, Germany), generating pET-24-sdhE. The sequence of the $s d h E$ insert was confirmed by DNA sequencing. BL21(DE3)-pCodonPlus-RIL (Stratagene) was first transformed with pRKISC containing the $E$. coli isc locus [15]. This plasmid has been successfully used for the production of iron-sulfur proteins [16]. In this study coexpression of the isc genes increased the yield of SdhE but was not essential. The resulting strain BL21(DE3)pCodonPlus-pRKISC was transformed with pET-24-sdhE for expression of $s d h E$ in $E$. coli.

For heterologous production of SdhE, E. coli transformants were grown in $1 \mathrm{~L}$ medium at $310 \mathrm{~K}$ on a magnetic stirrer $(1,000 \mathrm{rpm})$. The optimized expression medium contained the following per liter: $15 \mathrm{~g}$ yeast extract (Fluka), $20 \mathrm{~g}$ Bacto casamino acids, $2 \mathrm{~g} \mathrm{Na}{ }_{2} \mathrm{HPO}_{4} \cdot 2 \mathrm{H}_{2} \mathrm{O}$, $1 \mathrm{~g} \mathrm{KH}_{2} \mathrm{PO}_{4}$, and $8 \mathrm{~g} \mathrm{NaCl}$. After autoclaving, filter-sterilized components were added: kanamycin $(100 \mu \mathrm{g} / \mathrm{L})$, chloramphenicol $(50 \mu \mathrm{g} / \mathrm{L})$, tetracycline $(15 \mu \mathrm{g} / \mathrm{L})$, glucose $(2.5 \mathrm{~g} / \mathrm{L})$, cysteine/HCl $(177 \mathrm{mg} / \mathrm{L})$, and $\mathrm{FeCl}_{2} \cdot 4 \mathrm{H}_{2} \mathrm{O}$ $(10 \mathrm{mg} / \mathrm{L})$. At an optical density at $600 \mathrm{~nm}$ of $1.2, s d h E$ expression was induced by the addition of $1 \mathrm{mM}$ isopropyl $\beta$-D-thiogalactopyranoside. The culture was subsequently incubated for $24 \mathrm{~h}$ at $298 \mathrm{~K}$ with aeration, followed by an additional 24-h incubation without agitation. Cells were harvested by centrifugation and stored at $193 \mathrm{~K}$.

Purification of SdhE

The purification of SdhE was performed under anoxic conditions. Cells (4 g wet mass) were suspended in $20 \mathrm{~mL}$ 
$50 \mathrm{mM}$ tris(hydroxymethyl)aminomethane (Tris)/ $\mathrm{HCl} \mathrm{pH}$ 7.6 containing $2 \mathrm{mM}$ dithiothreitol (DTT). The suspension was passed three times through a French ${ }^{\circledR}$ press standard cell at $110 \mathrm{MPa}$. For in vitro reconstitution of the ironsulfur cluster [17], the following components were added to the crude lysate (final concentration): $\mathrm{Tris} / \mathrm{HCl} \mathrm{pH} 8.1$ $(75 \mathrm{mM}), \mathrm{FeCl}_{2}(0.54 \mathrm{mM})$, cysteine $(2 \mathrm{mM})$, DTT $(7 \mathrm{mM})$, and $\mathrm{Na}_{2} \mathrm{~S}(2 \mathrm{mM})$. The mixture $(100 \mathrm{~mL})$ was incubated with agitation for $12 \mathrm{~h}$ at $298 \mathrm{~K}$. Insoluble components were removed by centrifugation at $52,000 \mathrm{~g}$ for $1 \mathrm{~h}$. The supernatant was diluted $1: 3$ with $50 \mathrm{mM}$ Tris/ $\mathrm{HCl}$ pH 7.6 + 2 mM DTT and applied to a Q-Sepharose highperformance column $(2.6 \mathrm{~cm} \times 10 \mathrm{~cm}$; GE Healthcare, Munich, Germany) equilibrated with the same buffer. SdhE was eluted with $\mathrm{NaCl}$ using a step gradient. Nonreconstituted $\mathrm{SdhE}$ was eluted at $0.2 \mathrm{M} \mathrm{NaCl}$. The protein was concentrated and desalted by ultrafiltration (Amicon Ultra4, 10-kDa cut-off; Millipore, Eschborn, Germany). Reconstituted SdhE did not bind to the column material; therefore the flowthrough was concentrated and desalted by ultrafiltration (Amicon Ultra-4, 10-kDa cut-off; Millipore, Eschborn, Germany). The purified protein was more than 98\% pure as judged by sodium dodecyl sulfate polyacrylamide gel electrophoresis and its identity was confirmed by peptide mass fingerprinting. For enrichment of SdhE with ${ }^{57} \mathrm{Fe},{ }^{57} \mathrm{FeCl}_{3}$ was added to the E. coli medium and the in vitro reconstitution mixture at the concentrations indicated above. ${ }^{57} \mathrm{FeCl}_{3}$ was prepared by dissolving metallic ${ }^{57} \mathrm{Fe}$ (96\% enriched) (Chemotrade, Düsseldorf, Germany) in $36 \%(\mathrm{w} / \mathrm{v}) \mathrm{HCl}$ at $353 \mathrm{~K}$ for $12 \mathrm{~h}$.

\section{EPR spectroscopy measurements}

EPR spectra at $\mathrm{X}$-band $(9 \mathrm{GHz})$ were obtained with a Bruker EMX spectrometer. All spectra were recorded with a field modulation frequency of $100 \mathrm{kHz}$. Samples were cooled with an Oxford Instruments ESR 900 flow cryostat and an ITC4 temperature controller. Spin quantitations were carried out under nonsaturating conditions using $10 \mathrm{mM}$ copper perchlorate as the standard $(10 \mathrm{mM}$ $\mathrm{CuSO}_{4}, 2 \mathrm{mM} \mathrm{NaClO}_{4}, 10 \mathrm{mM} \mathrm{HCl}$ ). Temperature dependencies were determined under nonsaturating conditions. For all signals, the peak amplitude was measured at different temperatures. These values were used to obtain Curie plots describing the temperature behavior of the respective EPR signals. EPR spectra were simulated using our own programs based on formulas described earlier [18]. EPR-monitored redox titrations were performed at $293 \mathrm{~K}$ under a $\mathrm{N}_{2} / \mathrm{H}_{2}(95 / 5, \mathrm{v} / \mathrm{v})$ atmosphere. Potentials were adjusted with small amounts of freshly prepared sodium dithionite (10 or $100 \mathrm{mM}$ stock solutions) or freshly prepared potassium ferricyanide (15 or $150 \mathrm{mM}$ stock solutions). All redox potentials quoted here are expressed relative to the normal hydrogen electrode. In these titrations, a selection of redox mediators was used as described previously [12]. SdhE was added to a final concentration of $60 \mu \mathrm{M}$ in $50 \mathrm{mM}$ Tris/ $\mathrm{HCl} \mathrm{pH}$ 7.6. After equilibration at the desired potential, a $0.3-\mathrm{mL}$ aliquot was transferred to a calibrated EPR tube and immediately frozen in liquid nitrogen. The redox potential was measured with a $\mathrm{Ag} / \mathrm{AgCl}$ redox combination electrode (Mettler Toledo, Giessen, Germany). To obtain potentials relative to the normal hydrogen electrode, a value of $207 \mathrm{mV}$ (corresponding to the potential of $\mathrm{Ag} /$ $\mathrm{AgCl}$ at $298 \mathrm{~K}$ ) was added to the measured redox potentials.

\section{${ }^{57} \mathrm{Fe}$ ENDOR spectroscopy}

${ }^{57} \mathrm{Fe}$ ENDOR spectra were recorded at X-band with a commercial Bruker ELEXSYS E580 pulsed spectrometer. All experiments were performed at $5 \mathrm{~K}$, controlled with an Oxford Instruments helium-flow cryostat. ${ }^{57} \mathrm{Fe}$ DaviesENDOR spectra were acquired with the standard $\pi_{\text {prep }}-$ $\mathrm{RF}-\pi_{\mathrm{det}} / 2-\tau-\pi_{\mathrm{det}}$ sequence using selective microwave pulses at detection $\left(\pi_{\mathrm{det}}=200 \mathrm{~ns}\right)$ and a hard preparation pulse $\left(\pi_{\text {prep }}=50 \mathrm{~ns}\right)$ to suppress the overlapping proton hyperfine coupling [19]. RF pulse lengths were set to $8 \mu \mathrm{s}$ to account for the large gamma enhancement factor $\gamma_{\mathrm{enh}} \approx A_{\mathrm{iso}} / 2 v_{\mathrm{L}}$. A RF amplifier (Dressler) allowed a pulse power of about $1 \mathrm{~kW}$ between 5 and $40 \mathrm{MHz}$ with a linearity of 1-2 dB. Acquisition times varied between 3 and $12 \mathrm{~h}$, depending on the spectral position in the EPR line.

\section{Mössbauer spectroscopy}

Mössbauer data were recorded using a spectrometer with the usual alternating constant acceleration. The minimum experimental line width was $0.24 \mathrm{~mm} / \mathrm{s}$ (full width at half height). The sample temperature was maintained constant either in an Oxford Instruments Variox or in an Oxford Instruments Mössbauer-Spectromag cryostat. The latter is a split-pair superconducting magnet system for applied fields up to $8 \mathrm{~T}$ where the temperature of the sample can be varied in the range $1.5-250 \mathrm{~K}$. The field at the sample is perpendicular to the $\gamma$-beam. The ${ }^{57} \mathrm{Co} / \mathrm{Rh}$ source $(1.8 \mathrm{GBq})$ was positioned at room temperature inside the gap of the magnet system at a zero-field position. Isomer shifts are quoted relative to iron metal at $300 \mathrm{~K}$.

Magnetic Mössbauer spectra were simulated using the usual spin-Hamiltonian description for paramagnetic ironsulfur clusters:

$H_{e}=\mu_{\mathrm{B}} \boldsymbol{B} \cdot \mathbf{g} \cdot S_{\mathrm{t}}$,

where $S_{\mathrm{t}}$ is the total spin, and the values of the $\mathbf{g}$ matrix are taken from the EPR spectrum. The hyperfine interaction for 
${ }^{57} \mathrm{Fe}$ was calculated using the usual nuclear Hamiltonian [20].

\section{Zinc XAS}

For XAS spectroscopy, SdhE (13 mg protein in $1 \mathrm{~mL}$ $50 \mathrm{mM}$ Tris/ $\mathrm{HCl} \mathrm{pH} \mathrm{7.6)} \mathrm{was} \mathrm{concentrated} \mathrm{to} 0.1 \mathrm{~mL}$ by ultrafiltration using Amicon Ultra-4 centrifugal filter units (Millipore) with a $10-\mathrm{kDa}$ cut-off. Ethylene glycol was added to a final concentration of $20 \%$. The sample was placed into a $24 \mathrm{~mm} \times 3 \mathrm{~mm} \times 2 \mathrm{~mm}$ polycarbonate cuvette (with one $24 \mathrm{~mm} \times 3 \mathrm{~mm}$ wall consisting of 0.001-in. X-ray-transparent Mylar tape) and immediately frozen in liquid nitrogen. The final enzyme concentration was $2 \mathrm{mM}$ for SdhE. All buffers used for sample preparation were pretreated with Chelex 100 cation-exchange resin (Bio-Rad, Munich, Germany) and plastic materials were rinsed with $10 \mathrm{mM}$ EDTA and distilled water before use. Zinc X-ray absorption spectra were recorded and analyzed as described elsewhere [12].

Miscellaneous methods

Iron was quantified colorimetrically with neocuproin $(2,9-$ dimethyl-1,10-phenanthroline) and ferrozine [3-(2-pyridyl)-5,6-bis(4-phenylsulfonate)-1,2,4-triazine] as described by Fish [21]. Acid-labile sulfur was determined as methylene blue [22]. Zinc was determined using the metallochromic indicator 4-(2-pyridylazo)resorcinol [23] as described previously [24]. Protein concentration was determined by the bicinchoninic acid method [25] using the Pierce bicinchoninic acid protein assay kit (Thermo Scientific, Bonn, Germany) and bovine serum albumin as a standard.

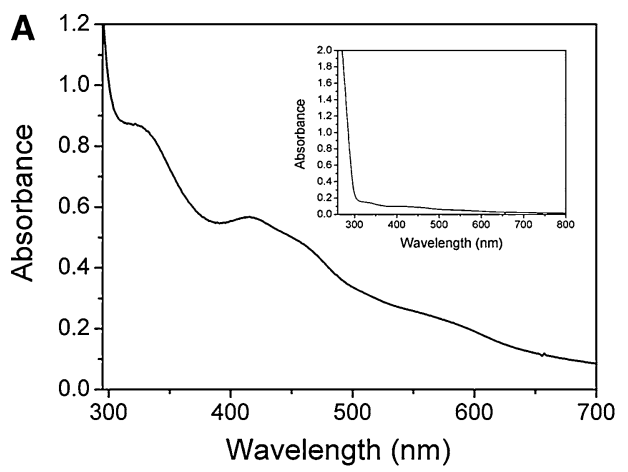

Fig. 2 UV-vis absorption spectra of SdhE produced in Escherichia coli. a Spectrum of purified $\operatorname{SdhE}(2.5 \mathrm{mg}$ protein $/ \mathrm{mL})$ obtained from cell extracts without reconstitution. The inset shows the spectrum of nonreconstituted SdhE after storage for 7 days. The same result was obtained with the addition of $0.1 \mathrm{mM}$ sodium dithionite and incubation for $60 \mathrm{~min}$. b Spectrum of $\operatorname{SdhE}(0.8 \mathrm{mg}$ protein $/ \mathrm{mL})$

\section{Results}

Characterization of heterologously produced $\mathrm{SdhE}$ by UV/vis and EPR spectroscopies

SdhE from $S$. solfataricus $\mathrm{P} 2$ was heterologously produced in E. coli following the procedure established for the production of $\mathrm{HdrB}$ [12]. The protein was purified from the $52,000 \mathrm{~g}$ supernatant by anion-exchange chromatography under anoxic conditions and analyzed for the presence of iron-sulfur centers. The brown SdhE protein (referred to as "nonreconstituted SdhE," see below) exhibited a UV/vis spectrum with maxima at 330 and $420 \mathrm{~nm}$ and broad shoulders at 460 and $570 \mathrm{~nm}$ (Fig. 2a). The protein contained $2.6 \pm 0.3 \mathrm{~mol}$ iron per mole of protein and $2.3 \pm 0.2 \mathrm{~mol}$ acid-labile sulfur per mole of protein. It showed a rhombic EPR signal with $g_{z y x}=2.017,2.008$, and 1.947 (Fig. 3, spectrum A). The spin concentration was, however, less than $10 \%$ of the protein concentration, corresponding to less than 0.04 spin per iron. Upon reduction with sodium dithionite or storage under anoxic conditions for several days, the major part of the absorbance was irreversibly lost, which indicated cluster breakdown (Fig. 2a, inset). These data basically confirm the data obtained previously [13]. A subsequent in vitro cluster reconstitution at the level of SdhE-containing E. coli cell extracts resulted in the formation of an ironsulfur cluster with altered spectroscopic properties. The $\mathrm{UV} / \mathrm{vis}$ spectrum of the purified protein after cluster reconstitution (referred to as "reconstituted protein") showed a broad absorption around $420 \mathrm{~nm}$ (Fig. 2b). Addition of sodium dithionite $(0.1 \mathrm{mM})$ did not change the spectrum (Fig. 2b, inset). Reconstituted SdhE contained $4.4 \pm 0.6 \mathrm{~mol}$ iron and $4.2 \pm 0.4 \mathrm{~mol}$ acid-labile

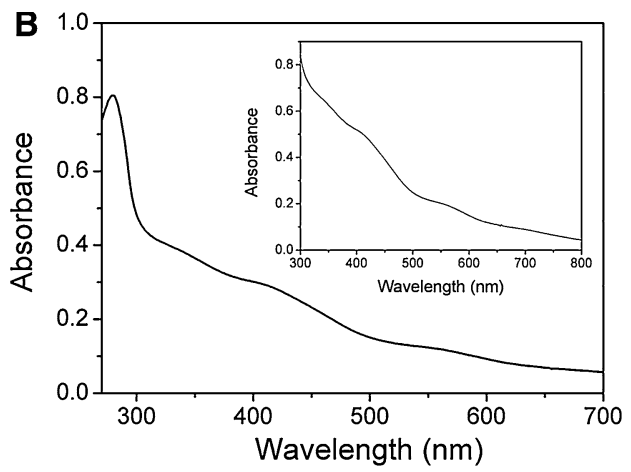

purified from cell extracts after in vitro reconstitution. The inset shows spectra of reconstituted SdhE after reduction by $0.1 \mathrm{mM}$ sodium dithionite. Protein samples were in $50 \mathrm{mM}$ tris(hydroxymethyl)aminomethane (Tris)/ $\mathrm{HCl} \mathrm{pH} \mathrm{7.6.} \mathrm{The} \mathrm{spectra} \mathrm{were} \mathrm{recorded}$ with a Zeiss Specord UV VIS S10 diode array spectrophotometer 


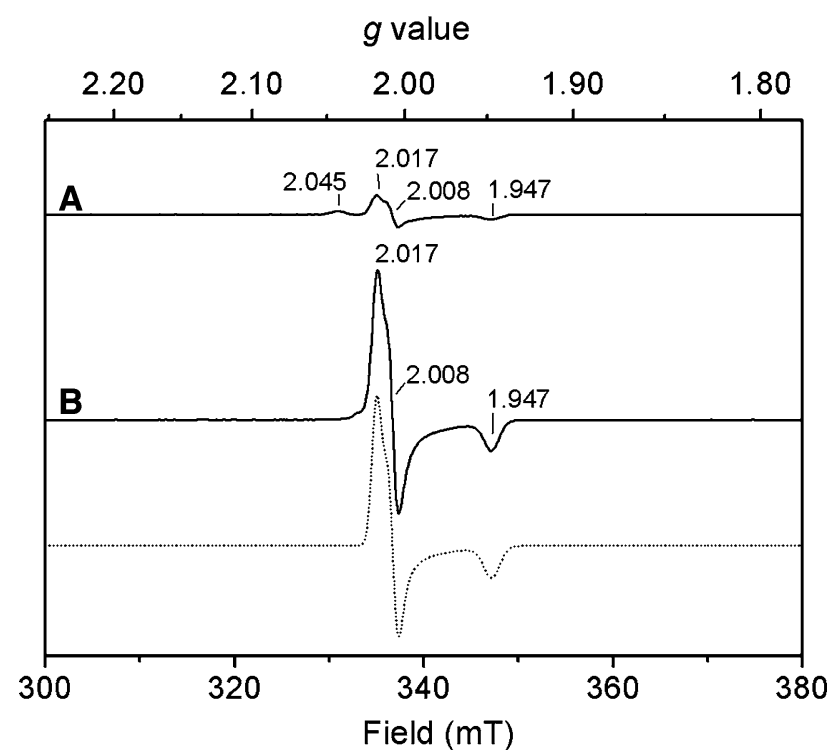

Fig. 3 Electron paramagnetic resonance (EPR) spectra of SdhE. A $\operatorname{SdhE}(100 \mu \mathrm{M})$ before reconstitution. $B \operatorname{SdhE}(100 \mu \mathrm{M})$ after reconstitution. SdhE was in $50 \mathrm{mM}$ Tris/HCl pH 7.6. The EPR conditions were as follows: temperature, $20 \mathrm{~K}$; microwave power, $2.007 \mathrm{~mW}$; microwave frequency, $9.458 \mathrm{GHz}$; modulation amplitude, $0.6 \mathrm{mT}$. The dotted line shows the simulation of spectrum $B$. The simulation parameters were as follows: $g_{z y x}=2.0175,2.0070$, $1.94711 ; W_{z y x}=1.0,1.0,1.7 \mathrm{mT}$

sulfur (1.8-fold higher than in nonreconstituted SdhE) per mole of protein. It also exhibited a rhombic EPR signal with $g_{z y x}=2.017,2.008$, and 1.947 (Fig. 3, spectrum B). Depending on the preparation, the spin concentration of this paramagnetic center was up to $70 \%$ of the protein concentration, corresponding to up to 0.16 spin per iron. Overall the spin concentration did not correlate with the iron and acid labile sulfur content in different preparations of reconstituted SdhE. These data support the presence of a diamagnetic and a paramagnetic $[4 \mathrm{Fe}-4 \mathrm{~S}]$ cluster in reconstituted $\mathrm{SdhE}$ (see below). In dye-mediated redox titrations performed in the redox range between -450 and $+200 \mathrm{mV}$, no change in the intensity of the $g_{z y x}=2.017$, 2.008, and 1.947 EPR signal was observed. In samples reduced by $2 \mathrm{mM}$ sodium dithionite $\left(E^{\circ \prime}=-511 \mathrm{mV}\right)$ the signal intensity decreased by about $30 \%$, which could not be reversed by the addition of an oxidant. Hence, reduction by sodium dithionite results in a partial degradation or conversion of the cluster. Consistently, in sodium dithionite reduced samples, a signal with $g_{z y x}=2.040,1.980$, and 1.836 typical for reduced $[2 \mathrm{Fe}-2 \mathrm{~S}]^{+}$clusters was detected. This signal could be observed at temperatures up to $60 \mathrm{~K}$ (Fig. 4a). The formation of this cluster is thought to be an artifact generated at very low redox potentials, as discussed below.

The $g_{z y x}=2.017,2.008$, and 1.947 signal was observed without loss of intensity in air-oxidized samples (12-h
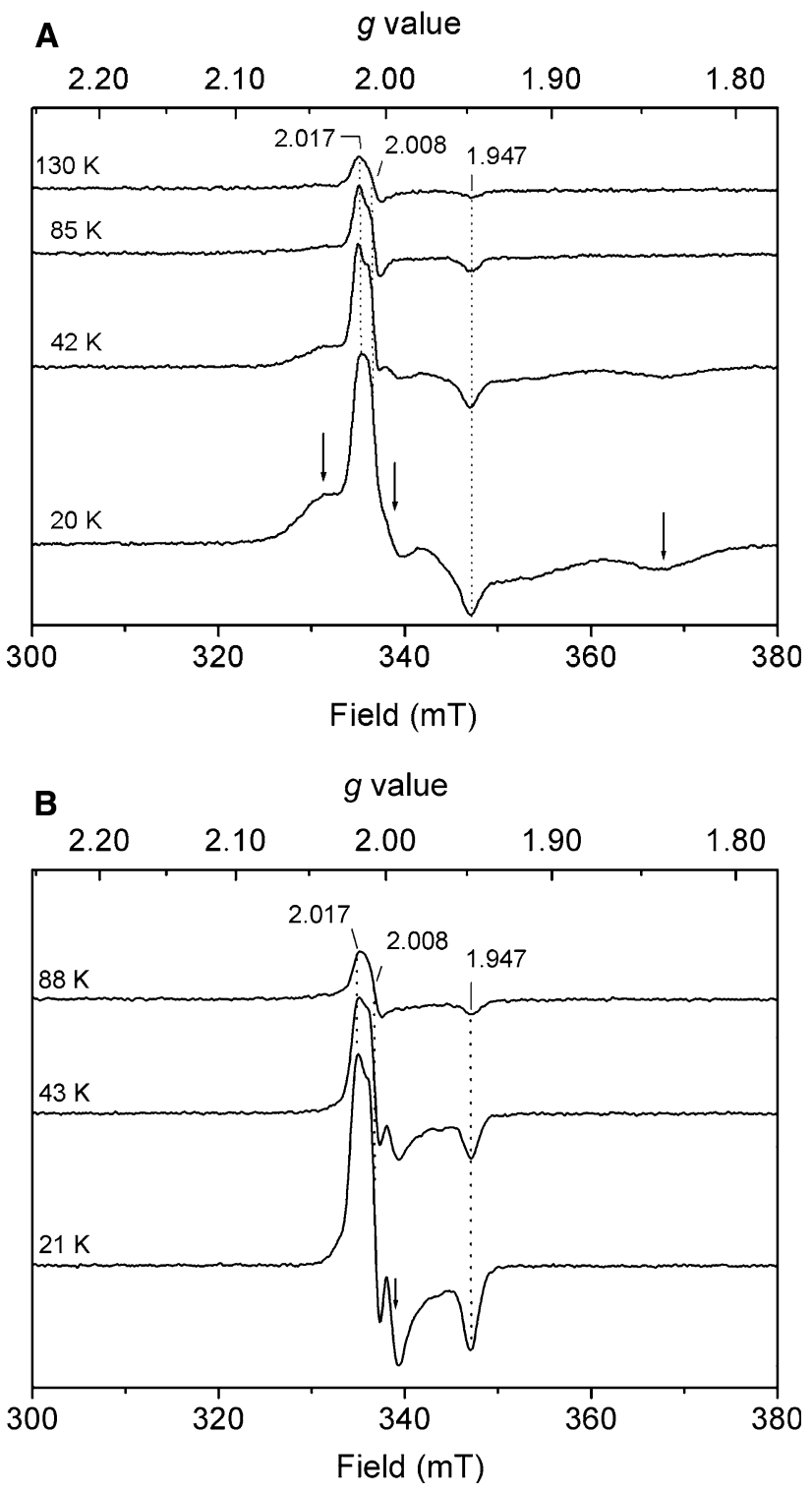

Fig. 4 EPR spectra of sodium dithionite reduced and duroquinoneoxidized SdhE at different temperatures. a $\operatorname{SdhE}(100 \mu \mathrm{M})$ was reduced by $2 \mathrm{mM}$ sodium dithionite. The arrows indicate the components of a $[2 \mathrm{Fe}-2 \mathrm{~S}]^{+}$signal. b SdhE $(100 \mu \mathrm{M})$ was oxidized by $2 \mathrm{mM}$ duroquinone. The arrow indicates the extra signal observed. The intensities of the spectra were not normalized for temperature. For EPR conditions see the legend to Fig. 3

incubation). Also incubation of SdhE with $2 \mathrm{mM}$ caldariella quinone, the physiological electron acceptor of Sulfolobus succinate dehydrogenase, or other quinones (e.g., duroquinone) did not change the intensity of the $g_{z y x}=2.017,2.008$, and 1.947 signal. Incubation with $1 \mathrm{mM}$ potassium ferricyanide $\left(E^{\circ \prime}=+356 \mathrm{mV}\right)$ resulted in an irreversible degradation of the cluster. Since the cluster was stable under air $\left(E^{\circ \prime}=+818 \mathrm{mV}\right)$, this degradation is probably caused by the complexation of iron by ferricyanide rather than by the oxidizing conditions [26]. 
In redox titrations at potentials higher than $-50 \mathrm{mV}$ a second signal in the $g=1.992$ region became detectable which overlapped with the $g_{z y x}=2.017,2.008$, and 1.947 signal (Fig. 4b). This signal was no longer detectable at temperatures above $90 \mathrm{~K}$, whereas the $g_{z y x}=2.017,2.008$, and 1.947 signal could still be detected at $150 \mathrm{~K}$ without signal broadening. The nature of the second paramagnetic species is not known.

Characterization of the iron-sulfur cluster in SdhE by ${ }^{57} \mathrm{Fe}$ ENDOR spectroscopy

Figure 5 displays ${ }^{57} \mathrm{Fe}$ Davies-ENDOR spectra of ${ }^{57} \mathrm{Fe}$ enriched SdhE recorded at different positions of the EPR line corresponding to the magnetic field parallel to the canonical orientations of the $g$ tensor. The spectra at $\boldsymbol{B} \| g_{z}$ and $\boldsymbol{B} \| g_{y}$ (low-field side) contain several broad features and are dominated by a strong absorption at around $16 \mathrm{MHz}$. At $\boldsymbol{B} \| g_{x}$ this strong absorption is attenuated and the spectrum becomes resolved into three distinct regions, centered at around $12.5,17.5$, and $23 \mathrm{MHz} .{ }^{57} \mathrm{Fe}$ ENDOR resonances of iron-sulfur clusters are usually characterized by doublets centered at half of the value of the orientationdependent hyperfine coupling $A$ and split by twice the ${ }^{57} \mathrm{Fe}$ Larmor frequency $\left(v_{\mathrm{L}}=0.48 \mathrm{MHz}\right.$ at 3,500 G), according to $v_{ \pm} \approx\left|A / 2 \pm v_{\mathrm{L}}\right|$. Because of the anisotropy of the hyperfine interaction and the spectral overlap of more than one iron site, doublets are not generally well resolved but result in strong featureless absorptions as observed at $\boldsymbol{B} \| g_{z}$ and $\boldsymbol{B} \| g_{y}$. In contrast, the ENDOR spectrum at $\boldsymbol{B} \| g_{x}$, with three resolved resonance regions, is indicative of at least three different types of iron site. The observed hyperfine couplings at this field orientation are summarized in Table 1 . The equivalency of iron sites 1 and 2 was deduced from the intensity of the ENDOR absorption at around $12.5 \mathrm{MHz}$ as compared with the regions at 17.5 and $23 \mathrm{MHz}$. However, a quantitative analysis could not be performed owing to the difficulties of subtracting the underlying proton resonances in this region. ${ }^{1}$ Experiments in Q-band are planned to overcome this issue.

For a more detailed understanding, we have compared the ENDOR spectra of SdhE with the ones of HdrB [12] recorded under similar experimental conditions (Fig. 5, dotted lines). We observe a striking similarity in the overall appearance of the spectra. A comparison of the better resolved spectra at $\boldsymbol{B} \| g_{x}$ indicates that the low-frequency absorption at around $12.5 \mathrm{MHz}$ is slightly shifted but the overall absorption shape is similar. Spectral simulations of

\footnotetext{
${ }^{1}$ The ${ }^{1} \mathrm{H}$ resonances are partially but not entirely subtracted by the pulse sequence employed. A reference experiment with ${ }^{56} \mathrm{Fe}$ led to a quality of data that was not sufficient for subtraction of the proton contribution, owing inherent problems with baseline distortion.
}

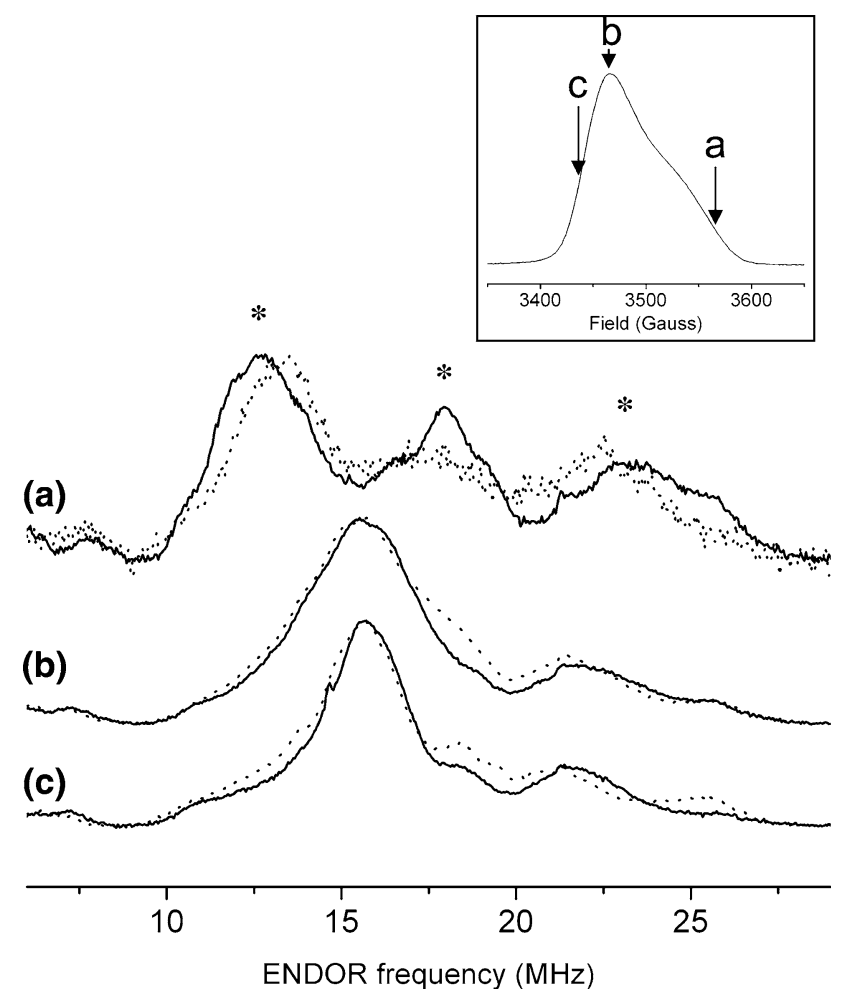

Fig. $5{ }^{57} \mathrm{Fe}$ Davies electron-nuclear double resonance (ENDOR) spectra. Solid lines represent the spectra of ${ }^{57} \mathrm{Fe}$-enriched SdhE recorded at different positions of the EPR line according to $a \boldsymbol{B} \| g_{x}, b$ $\boldsymbol{B} \| g_{y}$, and $c \boldsymbol{B} \| g_{z}$. The inset displays the selected fields in the EPR line. The ${ }^{57} \mathrm{Fe}$ spectra of $\mathrm{HdrB}$ from [12] are displayed as dotted lines. Visible ${ }^{57} \mathrm{Fe}$ doublets that we assign to three types of ${ }^{57} \mathrm{Fe}$ resonance are marked by asterisks. SdhE $(2 \mathrm{mM})$ was in $50 \mathrm{mM}$ Tris/ $\mathrm{HCl} \mathrm{pH}$ 7.6 containing $10 \%(\mathrm{v} / \mathrm{v})$ glycerol

CoM-HDR [19] reproduced this resonance with two almost equivalent iron sites, which were assigned to the ferric pair of a $[4 \mathrm{Fe}-4 \mathrm{~S}]^{3+}$ cluster. In contrast, the resonance region at 17.5 MHz (for $\boldsymbol{B} \| g_{x}$; Fig. 5, spectrum a) shows some peculiar differences. The ${ }^{57} \mathrm{Fe}$ absorption at $17.5 \mathrm{MHz}$, which is pronounced in SdhE, was not clearly distinguished in HdrB. Finally, the resonance around $22.5 \mathrm{MHz}$ is conserved in both SdhE and HdrB spectra. We conclude that the ${ }^{57} \mathrm{Fe}$ ENDOR spectrum of SdhE at $\boldsymbol{B} \| g_{x}$ reproduces resonances as previously observed in the spectra of $\mathrm{HdrB}$ and CoM-HDR and assigned to the ferric and mixedvalence pairs of a $[4 \mathrm{Fe}-4 \mathrm{~S}]^{3+}$ cluster. However, the presence of three distinct resonance regions seems indicative for a nonequivalency either in the ferric or in the mixedvalence iron sites and for the presence of a unique iron site.

Characterization of the iron-sulfur cluster in SdhE by Mössbauer spectroscopy

The zero-field Mössbauer spectrum of ${ }^{57} \mathrm{Fe}$-reconsituted $\mathrm{SdhE}$ at $80 \mathrm{~K}$ shows a number of resolved lines superimposed on a broad background contribution. Since the 
Table $1 g$ values and ${ }^{57} \mathrm{Fe}$ hyperfine couplings (MHz) of the clusters in the three CCG-domain-containing proteins [CoM-HDR (coenzyme $\mathrm{M}$ bound to HDR), HdrB, and SdhE] as compared with those of [4Fe-
$4 \mathrm{~S}]^{3+}$ clusters in model systems [50] and high-potential iron proteins $(H i P I P)$ [51] and for the fivefold-coordinated cluster in alkylated ferredoxin:thioredoxin reductase (NEM-FTR) [52]

\begin{tabular}{|c|c|c|c|c|c|c|c|c|}
\hline$[4 \mathrm{Fe}-4 \mathrm{~S}]^{3+}$ & {$\left[\mathrm{Fe}_{4} \mathrm{~S}_{4}\right]^{3+}$} & $\begin{array}{ll} & \text { HiPIP } \\
\text { E. } & \text { halophila }\end{array}$ & NEM-FTR & \multicolumn{2}{|c|}{ CoM-SH } & HdrB & \multicolumn{2}{|c|}{ SdhE } \\
\hline$g_{1}$ & 2.066 & 2.145 & 2.112 & \multicolumn{2}{|c|}{2.013} & 2.015 & \multicolumn{2}{|c|}{2.015} \\
\hline$g_{2}$ & 2.025 & 2.034 & 1.996 & \multicolumn{2}{|c|}{1.991} & 1.995 & \multicolumn{2}{|c|}{2.008} \\
\hline$g_{3}$ & 2.014 & 2.024 & 1.984 & \multicolumn{2}{|c|}{1.938} & 1.950 & \multicolumn{2}{|c|}{1.947} \\
\hline Fe site & $\begin{array}{c}a_{\text {iso }} \\
(\text { ENDOR) }\end{array}$ & $\begin{array}{c}a_{\text {iso }} \\
\text { (ENDOR) }\end{array}$ & $\begin{array}{c}a_{\text {iso }} \\
\text { (Mössbauer) }\end{array}$ & $\begin{array}{c}a_{\text {iso }} \\
\text { (ENDOR) }\end{array}$ & $\begin{array}{c}\left|A_{\mathrm{z}}\right| \\
(\mathrm{ENDOR})\end{array}$ & $\begin{array}{c}\left|A_{\mathrm{z}}\right| \\
(\mathrm{ENDOR})\end{array}$ & $\begin{array}{c}\left|A_{\mathrm{z}}\right| \\
\text { (ENDOR) }\end{array}$ & $\begin{array}{c}A_{\mathrm{z}} \\
\text { (Mössbauer) }\end{array}$ \\
\hline 1 & 17.4 & 21.6 & 22 & 29 & 25.7 & 26 & 25 & -11 \\
\hline 2 & 19.8 & 21.6 & 27 & 33.3 & 26.4 & 26 & 25 & -27 \\
\hline 3 & -32.7 & -33 & -37 & -39.2 & -46.6 & $?$ & 36 & 30.5 \\
\hline 4 & -33.5 & -33 & -37 & -43.4 & -48.7 & 46 & 46 & 45.7 \\
\hline Ref. & [50] & [51] & [52] & \multicolumn{2}{|c|}{ [19] } & [12] & \multicolumn{2}{|c|}{ This work } \\
\hline
\end{tabular}

${ }^{57}$ Fe hyperfine coupling values for $\mathrm{HdrB}$ and $\mathrm{SdhE}$ at one orientation $\left(A_{3}\right.$ for $\left.\boldsymbol{B} \| g_{x}\right)$ were extracted from the visible peaks in the electron-nuclear double resonance $(E N D O R)$ spectra. For SdhE, the positions of these peaks are marked by asterisks in Fig. 5

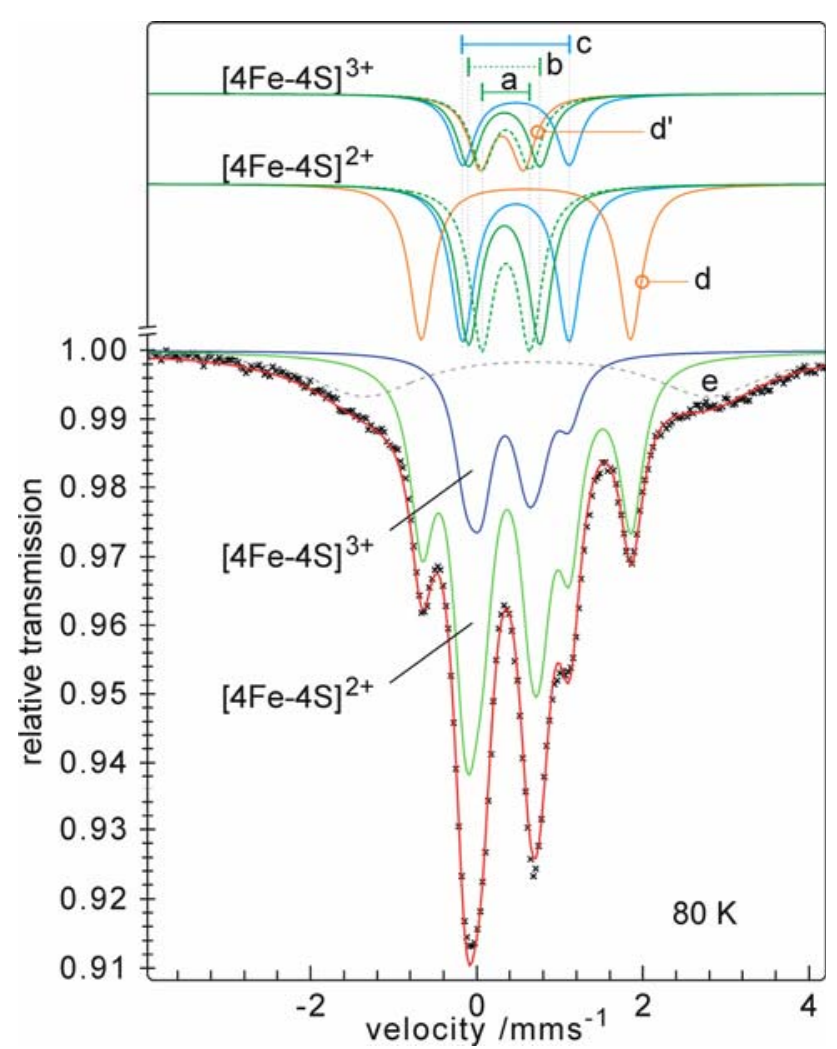

Fig. 6 Zero-field Mössbauer spectrum of ${ }^{57} \mathrm{Fe}$-reconstituted SdhE at $80 \mathrm{~K}$. The red line is based on a fit model with five Lorentzian doublets $\left(a-d, d^{\prime}\right)$ to account for two cubane clusters, indicated as $[4 \mathrm{Fe}-4 \mathrm{~S}]^{2+}$ and $[4 \mathrm{Fe}-4 \mathrm{~S}]^{3+}$. Doublet $e$ accounts for a broad background signal of $17 \%$. The Mössbauer parameters are given in Table 1. SdhE $(1 \mathrm{mM})$ was in $50 \mathrm{mM}$ Tris/ $\mathrm{HCl} \mathrm{pH} 7.6$ containing $10 \%(\mathrm{v} / \mathrm{v})$ glycerol asymmetric pattern, which is depicted in Fig. 6, essentially does not change at higher temperatures $(160 \mathrm{~K})$, spin relaxation must be fast and paramagnetic broadening can be excluded. The main resonances could be noticeably well fitted with five Lorentzian quadrupole doublets with identical line widths $\left(\mathrm{a}-\mathrm{d}, \mathrm{d}^{\prime}\right)$. However, an additional broad doublet $(e)$ had to be introduced to account for a broad background contribution. The moderately high isomer shift and large quadrupole splitting of the latter $(\delta=0.7 \mathrm{~mm} / \mathrm{s}$, $\Delta E_{\mathrm{Q}}=3.9 \mathrm{~mm} / \mathrm{s}$ ) indicate high-spin iron(II), most probably from nonspecifically bound inorganic sulfur complexes or pyrite-like precipitations that were formed during the ${ }^{57} \mathrm{Fe}$ reconstitution procedure. This contribution, which accounts for about $17 \%$ of the iron, will be mostly ignored in the following interpretations.

The intensities of the five Mössbauer subspectra (a-d, $d^{\prime}$ ) were constrained in the fit to comply with the presence of two cubane clusters in the ratio 30:70. In detail, $70 \%$ of the intensities of each of subspectra a-c was assigned to a $[4 \mathrm{Fe}-4 \mathrm{~S}]^{2+}$ cluster, and the remaining $30 \%$ was assigned to a $[4 \mathrm{Fe}-4 \mathrm{~S}]^{3+}$ cluster. In addition, subspectrum d $(70 \%$ abundant) belongs to the $[4 \mathrm{Fe}-4 \mathrm{~S}]^{2+}$ cluster, and subspectrum $d^{\prime}\left(30 \%\right.$ abundant) belongs to the $[4 \mathrm{Fe}-4 \mathrm{~S}]^{3+}$ cluster. The two sets of subspectra are visualized as separate contributions in Fig. 6 and the Mössbauer parameters are summarized in Table 2.

The allocation of a diamagnetic $[4 \mathrm{Fe}-4 \mathrm{~S}]^{2+}$ and a paramagnetic $[4 \mathrm{Fe}-4 \mathrm{~S}]^{3+}$ cluster is motivated and supported by the following major observations and arguments:

1. Applied-field measurements (given later) reveal diamagnetic behavior for $70 \%$ of the Mössbauer sample. 
Table 2 Mössbauer parameters of ${ }^{57} \mathrm{Fe}$-reconstituted SdhE at $80 \mathrm{~K}$, obtained from the fit shown in Fig. 5

\begin{tabular}{llll}
\hline Doublet & Relative abundance ${ }^{\mathrm{a}}$ & $\delta(\mathrm{mm} / \mathrm{s})$ & $\Delta E_{\mathrm{Q}}(\mathrm{mm} / \mathrm{s})$ \\
\hline $\mathrm{a}$ & $0.7+0.3$ & 0.36 & 0.58 \\
$\mathrm{~b}$ & $0.7+0.3$ & 0.34 & 0.86 \\
$\mathrm{c}$ & $0.7+0.3$ & 0.48 & 1.28 \\
$\mathrm{~d}$ & 0.7 & 0.60 & 2.52 \\
$\mathrm{~d}^{\prime}$ & 0.3 & 0.31 & 0.52 \\
\hline
\end{tabular}

The line width was $0.34 \mathrm{~mm} / \mathrm{s}$ for all subspectra.

a The line intensities are constrained to comply with two clusters, a $[4 \mathrm{Fe}-4 \mathrm{~S}]^{2+}$ cluster comprising 0.7 equivalents $(\mathrm{a}+\mathrm{b}+\mathrm{c})+(\mathrm{d})$, and a $[4 \mathrm{Fe}-4 \mathrm{~S}]^{3+}$ cluster comprising 0.3 equivalents $(\mathrm{a}+\mathrm{b}+\mathrm{c})$ $+\left(d^{\prime}\right)$

2. The integration of an EPR spectrum recorded from an aliquot of the Mössbauer sample supported the ratio. The spin concentration was about $30 \%$ of the protein concentration (not shown).

3. The presence of oxidized $[2 \mathrm{Fe}-2 \mathrm{~S}]^{2+}$ clusters, which would be the alternative candidate for a diamagnetic iron-sulfur cluster, can be excluded since only mixedvalence iron-sulfur sites are found (as will be discussed later). For the same reason paramagnetic $[3 \mathrm{Fe}-4 \mathrm{~S}]^{1+}$ clusters can also be discarded, since they are all-ferric species.

4. Reduced $[2 \mathrm{Fe}-2 \mathrm{~S}]^{+}$clusters as alternative possible paramagnetic species are excluded from EPR spectra and the magnetic Mössbauer spectra given later.

The $[4 \mathrm{Fe}-4 \mathrm{~S}]^{2+}$ cluster

The isomer shifts of subspectra a-d) scatter almost in the full range known for iron-sulfur clusters [27, 28]. However, the average of the individual values, $\delta_{\mathrm{av}}=0.45 \mathrm{~mm} / \mathrm{s}$, which may be taken as a measure to assess the "mean" valence per iron in the cluster, matches nicely the value expected for $[4 \mathrm{Fe}-4 \mathrm{~S}]^{2+}$ clusters: mixed-valence $\mathrm{Fe}^{2.5+}$ (formally two $\mathrm{Fe}^{2+}$ and two $\mathrm{Fe}^{3+}$ ) [27-30]. The same comparison holds for the average quadrupole splitting, $\Delta E_{\mathrm{Q}, \mathrm{av}}=1.28 \mathrm{~mm} / \mathrm{s}$, which is also typical for $[4 \mathrm{Fe}-4 \mathrm{~S}]^{2+}$ clusters.

The most remarkable feature of the zero-field Mössbauer spectrum of the $[4 \mathrm{Fe}-4 \mathrm{~S}]^{2+}$ cluster is the unique doublet (d) with an isomer shift of $0.6 \mathrm{~mm} / \mathrm{s}$. According to the empirical relation, $\delta=1.43-0.4 \mathrm{~s}$, that was found for Mössbauer isomer shifts and the oxidation state $s$ of iron in tetrahedral $\left\{\mathrm{FeS}_{4}\right\}$ sites [31], this subspectrum represents an iron site with pure ferrous character $(s=2.0)$. The large quadrupole splitting is another indication of the corresponding high-spin $3 d^{6}$ electron configuration. However, such a localized valence is rather unusual for $[4 \mathrm{Fe}-4 \mathrm{~S}]^{2+}$ clusters, which typically exhibit extensive charge delocalization and more or less the same $\mathrm{Fe}^{2.5+}$ character for all sites. In contrast, ferrous ions with localized valence are usually regarded as a rather unique and typical feature of reduced $[2 \mathrm{Fe}-2 \mathrm{~S}]^{+}$clusters with spin $S=1 / 2[27,28,32]$. However, we can exclude this possibility here because subspectrum $\mathrm{d}$ in fact belongs to a diamagnetic cluster, as one can infer from the applied-field spectra shown in Fig. 7. Moreover, the EPR spectrum recorded from an aliquot of the Mössbauer sample (not shown) does not exhibit any indication of the rhombic absorption pattern with $g_{\text {av }}<2$ and a noticeably low $g_{\text {min }}$ in the range 1.9-1.8 that is typical of $[2 \mathrm{Fe}-2 \mathrm{~S}]^{+}$clusters. Instead, the individual iron sites of the diamagnetic $[4 \mathrm{Fe}-4 \mathrm{~S}]^{2+}$ cluster are rather heterogeneous and show partial valence localization, which is particularly strong for one unique ferrous site.

The $[4 \mathrm{Fe}-4 \mathrm{~S}]^{3+}$ cluster

Since the paramagnetic cluster found by EPR/ENDOR spectroscopy appears to be an oxidized $[4 \mathrm{Fe}-4 \mathrm{~S}]^{3+}$ cluster,

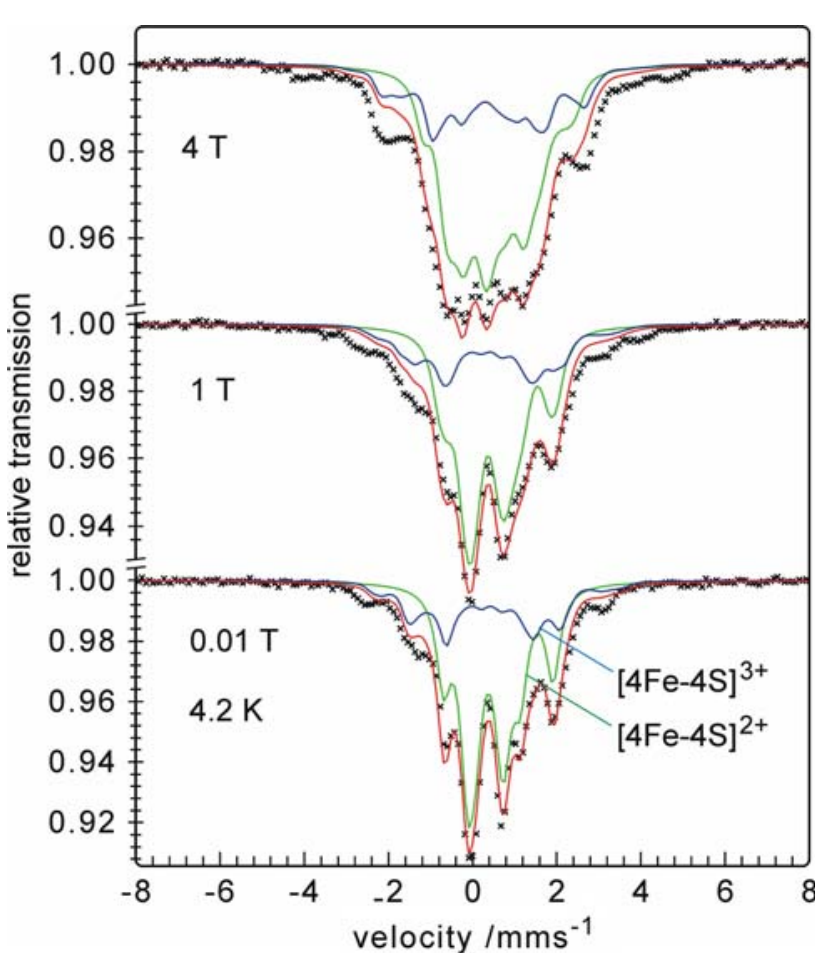

Fig. 7 Magnetic Mössbauer spectra of ${ }^{57} \mathrm{Fe}$-reconstituted SdhE at $4.2 \mathrm{~K}$ with fields of $0.01,1$, and $4 \mathrm{~T}$ applied perpendicular to the $\gamma$ rays. The red line is a spin-Hamiltonian simulation for the superposition of the subspectra from a paramagnetic $[4 \mathrm{Fe}-4 \mathrm{~S}]^{3+}$ cluster with spin $S=1 / 2(30 \%)$ and a diamagnetic $[4 \mathrm{Fe}-4 \mathrm{~S}]^{2+}$ cluster with $S=0$. The same five subspectra $\left(a-d, d^{\prime}\right)$ were used as for Fig. 6, with isomer shifts and quadrupole splitting as given in Table 1 $(0.02 \mathrm{~mm} / \mathrm{s}$ was added to $\delta$ to account for the lower temperature). All quadrupole values were taken to be positive with asymmetry parameters $\eta=0.1,1.0,0.9,0.1$ for subspectra $a-d$ of $[4 \mathrm{Fe}-4 \mathrm{~S}]^{2+}$, and $\eta=0.9,0.8,0.8,0.0$ for subspectra $a-c$ and $d^{\prime}$ of $[4 \mathrm{Fe}-4 \mathrm{~S}]^{3+}$. The hyperfine coupling constants are given in Table S1 
we introduced a group of four doublets into our Mössbauer fit model, for which three $(\mathrm{a}-\mathrm{c})$, are the same as for the $[4 \mathrm{Fe}-$ $4 \mathrm{~S}]^{2+}$ cluster, but a new doublet $\left(\mathrm{d}^{\prime}\right)$ was invoked with clear ferric character (low isomer shift), in contrast to the ferrous properties of doublet $\mathrm{d}$ in the $2+$ cluster. This simple approach was suggested by the result of a preliminary fit with only four doublets that showed the presence of surplus ferric contributions in the spectra. For this estimate the resolved doublet (d) could be taken as a nice marker for the intensity of a single iron site in a particular cubane cluster (see the electronic supplementary material). Global optimization of the five separate subspectra $\left(a-d, d^{\prime}\right)$ with constrained intensities yielded a nice fit as shown in Fig. 6. We take this as proof of the presence of two cubane clusters and that the paramagnetic cluster is more oxidized than the diamagnetic $[4 \mathrm{Fe}-4 \mathrm{~S}]^{2+}$ cluster. Variations of the contribution from the oxidized cluster yielded the best results at a relative concentration of $30 \%( \pm 5)$ (neglecting the Mössbauer background signals), which is close to the spin quantification obtained by EPR for the ${ }^{57} \mathrm{Fe}$-enriched Mössbauer sample. We have to note that the fit of the Mössbauer subspectra a-c and $\mathrm{d}^{\prime}$ presented here has to be taken as a generic solution, rather than being final and unique. We have to refrain, however, from further sophistication because of the severe overlap of the subspectra. This also holds for the appliedfield measurements reported in the following.

\section{Magnetic Mössbauer spectra}

The expected diamagnetic behavior of the $[4 \mathrm{Fe}-4 \mathrm{~S}]^{2+}$ cluster and the paramagnetic character of the $[4 \mathrm{Fe}-4 \mathrm{~S}]^{3+}$ clusters, respectively, were probed with applied-field Mössbauer spectra recorded at $4.2 \mathrm{~K}$, as shown in Fig. 7. About $83 \%( \pm 10)$ of the total intensity of each experimental spectrum could be nicely fitted with the two corresponding magnetic subspectra, for which the isomer shifts, quadrupole splittings, and intensity ratios were taken from subspectra a$\mathrm{d}$ and $\mathrm{d}^{\prime}$ found at zero-field condition (isomer shifts were corrected for second-order Doppler shift at $4.2 \mathrm{~K}$ by adding $+0.02 \mathrm{~mm} / \mathrm{s}$ to the values obtained at $80 \mathrm{~K}$ ). Note that the missing intensities, particularly at the wings of the absorption pattern, are mostly due to the background signal (e) with $17 \%$ intensity, were ignored here. The fit reproduces nicely the resolved main features of the spectra. In particular it reveals the diamagnetic properties of the unique "ferrous" site (d) from the $[4 \mathrm{Fe}-4 \mathrm{~S}]^{2+}$ cluster with spin $S=0$. This is seen best for the line at $2 \mathrm{~mm} / \mathrm{s}$, which does not split in weak applied fields up to $1 \mathrm{~T}$, owing to the absence of an internal field. At $4 \mathrm{~T}$ the diamagnetic spectrum also yields magnetic splitting due to the nuclear Zeeman effect, but again without contributions from internal fields.

Because of the low abundance of the paramagnetic $[4 \mathrm{Fe}-4 \mathrm{~S}]^{3+}$ cluster and because of the unknown properties of the overlapping background iron(II) contribution, we did not optimize the magnetic hyperfine tensor components for that cluster. We rather adopted the $[4 \mathrm{Fe}-4 \mathrm{~S}]^{3+}$ cluster of oxidized alkylated ferredoxin:thioredoxin reductase (NEMFTR) as a possible "model system," which may have some similarities with oxidized SdhE since it also exhibits rather distinct iron sites, which have been thoroughly studied [33]. The components of the $A$ tensors from that system were used for the simulation and slightly adapted, if necessary. The final values are in the range $-33 \mathrm{~T} \leq$ $A / g_{\mathrm{N}} \mu_{\mathrm{N}} \leq 22 \mathrm{~T}$, which comprises the range of ENDOR resonances described earlier. The Mössbauer parameters are reported in Table 2 and the values of the hyperfine coupling constant are summarized in Table S1.

In conclusion, the Mössbauer spectra of ${ }^{57} \mathrm{Fe}$-reconstituted SdhE "as such" support the conclusion derived from the ENDOR data, that the protein in its "native" state has a $[4 \mathrm{Fe}-4 \mathrm{~S}]^{3+}$ cluster with a unique site $\left(\mathrm{d}^{\prime}\right)$. The Mössbauer study is complementary to the EPR/ENDOR investigation in that it also detected a diamagnetic $[4 \mathrm{Fe}-4 \mathrm{~S}]^{2+}$ cluster, which is even the major species in the concentrated Mössbauer/ EPR sample. We presume that both states belong to the same cluster. The unique iron site is even more pronounced for the diamagnetic state of the cluster. The high isomer shift and large quadrupole splitting are typical of a localized ferrous valence. Upon oxidation, the charge seems to be mostly released from that unique iron site $(d)$, since in the $3+$ state that iron $\left(\mathrm{d}^{\prime}\right)$ adopts strong ferric character, whereas the other sites are little or not affected.

XAS analysis of a zinc site in SdhE

In a previous study recombinant, nonreconstituted SdhE from $S$. tokodaii was shown to contain an isolated zinc site with an $\mathrm{S}_{3}(\mathrm{~N} / \mathrm{O})_{1}$ coordination sphere [13]. Both, reconstituted and nonreconstituted SdhE contained $1.3 \pm 0.3 \mathrm{~mol}$ zinc per mole of protein. The iron to zinc ratio was $2: 1$ for nonreconstituted SdhE and 3.4:1 for the reconstituted protein. Zinc K-edge XAS measurements on reconstituted SdhE from $S$. solfataricus showed that this zinc site is also present after chemical reconstitution of the $[4 \mathrm{Fe}-4 \mathrm{~S}]$ cluster (Fig. 8, Table 3). Hence, this site is not formed by the binding of zinc to unoccupied cysteine residues in the nonreconstituted protein.

\section{Discussion}

SdhE is a member of the CCG domain family. The analysis of recombinant $\mathrm{SdhE}$ in previous studies by UV/vis, resonance Raman, and X-ray absorption spectroscopies indicated that the protein contains a labile $[2 \mathrm{Fe}-2 \mathrm{~S}]$ cluster as the predominant cluster species $[13,14]$. We showed in 

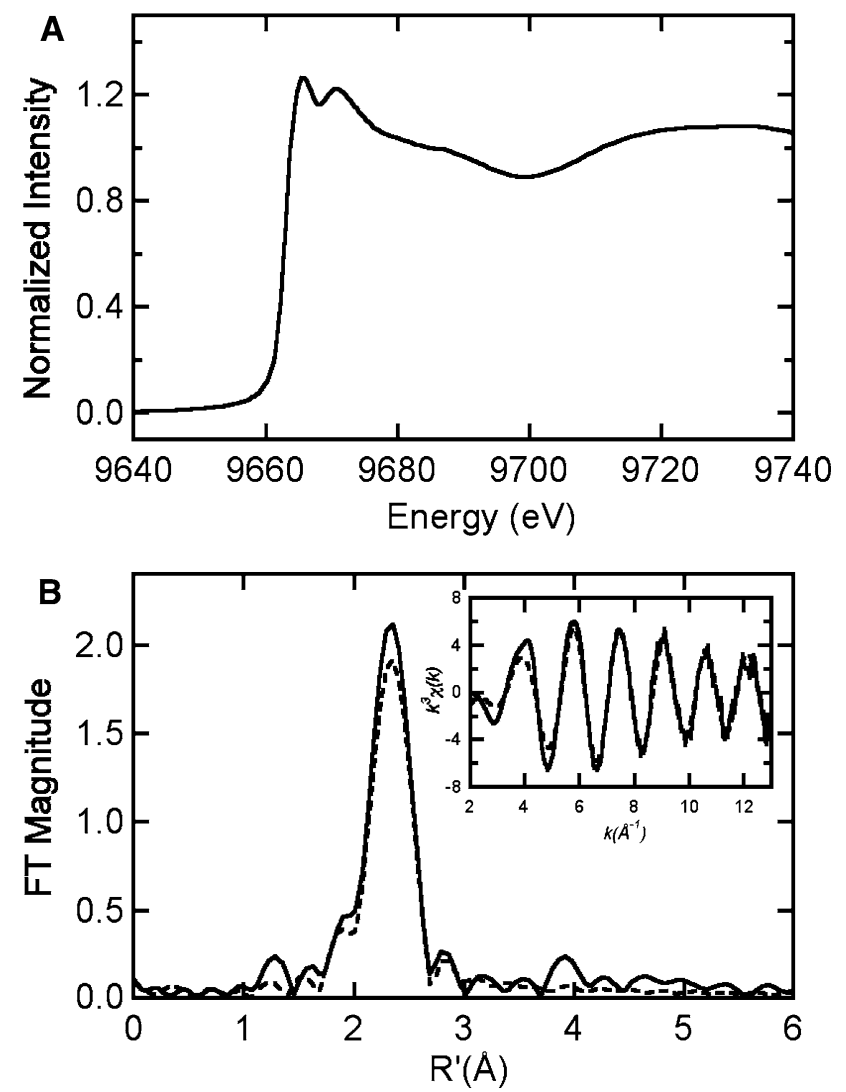

Fig. 8 Zinc K-edge X-ray absorption spectrum (a), $k^{3}$-weighted extended X-ray absorption fine structure spectrum (b, inset), and Fourier transform $(F T)\left(k^{3}\right.$-weighted, $\left.k=2-13 \AA^{-1}\right)(\mathbf{b})$ of $\mathrm{SdhE}$. Dashed lines in $\mathbf{b}$ represent the best-fit simulation (fit 7, Table 3)

this study that after an in vitro cluster reconstitution of heterologously produced SdhE, an iron-sulfur cluster stable over a wide redox range is formed. ${ }^{57} \mathrm{Fe}$ Mössbauer spectra of reconstituted SdhE at zero field showed a number of resolved doublets that could be interpreted by the superposition of a diamagnetic $[4 \mathrm{Fe}-4 \mathrm{~S}]^{2+}$ cluster and of the corresponding oxidized form $[4 \mathrm{Fe}-4 \mathrm{~S}]^{3+}$.

The oxidized form of the cluster is paramagnetic and exhibited a rhombic EPR signal with $g_{z y x}=2.017,2.008$, and 1.947. The spin concentration of this paramagnetic species accounted for up to $70 \%$ of the SdhE concentration, depending on the protein preparation. In redox titrations of SdhE the spin concentration of the paramagnetic cluster did not change over a wide redox range, indicating that the diamagnetic form and the paramagnetic form of the $[4 \mathrm{Fe}-4 \mathrm{~S}]$ cluster are arrested in their redox state and cannot be interconverted by a simple redox reaction. This suggests that the reconstitution results in some heterogeneity of the protein conformation which affects the redox potentials of the cluster.

Two lines of evidence suggest that at least the paramagnetic cluster is of physiological relevance:

1. Native respiratory complex II from $S$. tokodaii exhibits an EPR signal with $g_{z y x}=2.016,2.00$, and 1.957 [7, 13] reminiscent of the signal observed here for reconstituted SdhE. In complex II this signal was detectable in samples incubated with the physiological electron donor sodium succinate $\left(E^{\circ \prime}=+30 \mathrm{mV}\right)$ but was no longer detectable in samples reduced with sodium dithionite $\left(E^{\circ \prime}=-511 \mathrm{mV}\right)$. These data strongly indicate that the paramagnetic form of the $[4 \mathrm{Fe}-4 \mathrm{~S}]$ cluster observed in recombinant $\mathrm{SdhE}$ is also present in native complex II under physiological redox conditions. It had not been addressed in these studies if the loss of the EPR signal in native complex II in the presence of sodium dithionite is due to cluster reduction or cluster degradation.

Table 3 Curve-fitting results for zinc extended X-ray absorption fine structure

\begin{tabular}{|c|c|c|c|c|c|c|c|}
\hline Sample filename ( $k$ range) $\Delta k^{3} \chi$ & Fit & Shell & $R_{\text {as }}(\AA)$ & $\sigma_{\text {as }}^{2}\left(\AA^{2}\right)$ & $\Delta E_{0}(\mathrm{eV})$ & $f^{\mathrm{a}}$ & $\mathrm{BVS}^{\mathrm{b}}$ \\
\hline SdhE & 1 & $\mathrm{Zn}-\mathrm{S}_{3}$ & 2.32 & 0.0033 & 0.221 & 0.097 & 1.61 \\
\hline $\operatorname{ZSD} 0 A\left(2-13 \AA^{-1}\right)$ & 2 & $\mathrm{Zn}-\mathrm{S}_{4}$ & 2.32 & 0.0050 & 1.591 & 0.076 & 2.15 \\
\hline \multirow[t]{8}{*}{$\Delta k^{3} \chi=12.52$} & 3 & $\mathrm{Zn}-\mathrm{S}_{5}$ & 2.32 & 0.0065 & 1.273 & 0.065 & 2.69 \\
\hline & 4 & $\mathrm{Zn}-\mathrm{S}_{6}$ & 2.32 & 0.0079 & 0.957 & 0.061 & 3.22 \\
\hline & \multirow[t]{2}{*}{5} & $\mathrm{Zn}-\mathrm{S}_{1}$ & 2.37 & -0.0023 & \multirow[t]{2}{*}{8.627} & \multirow[t]{2}{*}{0.081} & \multirow[t]{2}{*}{1.47} \\
\hline & & $\mathrm{Zn}-\mathrm{O}_{3}$ & 2.11 & {$[0.0025]^{\mathrm{c}}$} & & & \\
\hline & \multirow[t]{2}{*}{6} & $\mathrm{Zn}-\mathrm{S}_{2}$ & 2.34 & 0.0005 & \multirow[t]{2}{*}{3.756} & \multirow[t]{2}{*}{0.072} & \multirow[t]{2}{*}{1.78} \\
\hline & & $\mathrm{Zn}-\mathrm{O}_{2}$ & 2.06 & {$[0.0025]^{\mathrm{c}}$} & & & \\
\hline & \multirow[t]{2}{*}{7} & $\mathrm{Zn}-\mathrm{S}_{3}$ & 2.34 & 0.0025 & \multirow[t]{2}{*}{2.763} & \multirow[t]{2}{*}{0.063} & \multirow[t]{2}{*}{1.93} \\
\hline & & $\mathrm{Zn}-\mathrm{O}_{1}$ & 2.04 & {$[0.0025]^{\mathrm{c}}$} & & & \\
\hline
\end{tabular}

Shell is the chemical unit defined for the multiple scattering calculation. Subscripts denote the number of scatterers per metal. $R_{\text {as }}$ is the metalscatterer distance. $\sigma_{\text {as }}^{2}$ is a mean square deviation in $R_{\text {as }} . \Delta E_{0}$ is the shift in $E_{0}$ for the theoretical scattering functions

${ }^{\text {a }} f^{\prime}$ is a normalized error $\left(\chi^{2}\right): f=\frac{\left\{\sum_{i}\left[k^{3}\left(\chi_{i}^{\text {obs }}-\chi_{i}^{\text {alc }}\right)\right]^{2} / N\right\}^{1 / 2}}{\left[\left(k^{3} \chi^{\text {obs }}\right)_{\max }-\left(k^{3} \chi^{\text {obs }}\right)_{\min }\right]}$

${ }^{\mathrm{b}} \mathrm{BVS}=\Sigma \exp \left[\left(r_{0}-R_{\mathrm{as}}\right) / \mathrm{B}\right], B=0.37, r_{0}(\mathrm{Zn}(\mathrm{II})-\mathrm{S})=2.09, r_{0}(\mathrm{Zn}(\mathrm{II})-\mathrm{O})=1.704$ [53]

c Numbers in square brackets were fixed at the indicated values and not optimized 
2. The $g$ value anisotropy of the $g_{z y x}=2.017,2.008$, and 1.947 signal in SdhE is reminiscent of EPR signals observed in the oxidized state of other enzymes with CCG-domain-containing subunits [34-37]. From these enzymes HDR from M. marburgensis has been studied most extensively. The enzyme forms a stable paramagnetic reaction intermediate (referred to as CoM-HDR) with $g_{z y x}=2.013,1.991$, and 1.938. This paramagnet was shown to reside on the CCG-domain-containing subunit $\mathrm{HdrB}$ in studies with recombinant $\mathrm{HdrB}$ $\left(g_{z y x}=2.015,1.995\right.$, and 1.950). In both native HDR and recombinant HdrB the paramagnetic species was shown to be an oxidized species which could be reduced to the diamagnetic form with a midpoint potential of $-185 \mathrm{mV}$ (versus the normal hydrogen electrode at $\mathrm{pH}$ 7.6) and $-175 \mathrm{mV}$ (versus the normal hydrogen electrode at $\mathrm{pH} 7.6)$, respectively $[12,34] .{ }^{57}$ Fe ENDOR spectroscopy revealed that the paramagnetic species in oxidized native HDR and oxidized $\mathrm{HdrB}$ is a $[4 \mathrm{Fe}-4 \mathrm{~S}]^{3+}$ cluster $[12,19]$. The paramagnetic cluster in SdhE showed $g$ values and ${ }^{57} \mathrm{Fe}$ hyperfine couplings similar to those previously observed for CoM-HDR and HdrB (Table 1).

Furthermore, we provided here the first analysis of a CCG domain cluster by Mössbauer spectroscopy. The Mössbauer data clearly indicate the presence of a $[4 \mathrm{Fe}-4 \mathrm{~S}]$ cluster in SdhE. Both zero-field and applied-field spectra are consistent with the presence of a distinct doublet with a remarkable high isomer shift that could be attributed to a unique iron site. The high isomer shift is reminiscent of the shift observed in the Mössbauer spectra of NEM-FTR [33] and also of synthetic [4Fe-4S] clusters containing a fivefold coordinated iron [38]. As the CCG domain contains two copies of five cysteines, one possibility would be that five cysteines of one copy provide five ligands to the cluster. However, this hypothesis is not consistent with our mutagenesis experiments on the HdrB cluster, which showed that only four of the five cysteines in the C-terminal CCG domain are essential for cluster formation [12]. As an alternative, another amino acid could provide the fifth ligand. This hypothesis is appealing since a different type of ligand could account for the differences of the $g$ values in particular for the cluster in NEM-FTR, as reported in Table 1. In CCGdomain-containing proteins a histidine residue (His121 in HdrB and SdhE) located between the N-terminal and the $\mathrm{C}$-terminal CCG domain is highly conserved. This residue is a good candidate for an extra ligand. This proposal needs to be experimentally proven.

While the cluster in $\mathrm{HdrB}$ has a catalytic function mediating the reduction of a disulfide in two one-electron steps [39, 40], the function of the cluster in SdhE is still elusive. Two possible functions can be envisaged.
The cluster could have an electron transfer role mediating the electron transfer from the iron-sulfur clusters in $\mathrm{SdhB}$ to the quinone pool, provided that the cluster is redox-active at physiological redox potentials. Alternatively, the cluster could have a structural role as has been observed for other iron-sulfur clusters [41, 42]. In this case electrons might be directly transferred from the iron-sulfur cluster S3 in subunit $\mathrm{SdhB}$ to the quinone pool as in E. coli quinol:fumarate oxidoreductase (type D enzyme) [43, 44]. SdhE shares several conserved $\alpha$-helices with related CCGdomain-containing proteins. Wheel projections of these conserved helices predict that several amphipathic $\alpha$-helices can be formed, which led to the hypothesis that $\mathrm{SdhE}$ anchors complex II monotopically in the membrane [9, 45]. The iron-sulfur cluster could function as a scaffold for the proper positioning of the predicted amphipathic helices and could be involved in binding and positioning the quinone. CCG-domain-containing subunits are also found in other enzymes mediating electron transfer to the quinone pool, e.g., anaerobic glycerol 3-phosphate dehydrogenase [46] and glycolate oxidase [47]. The corresponding subunits of these enzymes are also thought to function as monotopic membrane anchors.

In addition to a [4Fe-4S] cluster, both $\mathrm{HdrB}$ and $\mathrm{SdhE}$ also harbor an isolated zinc site with an $\mathrm{S}_{3}(\mathrm{O} / \mathrm{N})_{1}$ coordination [12, 13]. This zinc site has also been detected in native HDR [12]. Site-directed mutagenesis of $\mathrm{HdrB}$ identified four cysteine residues in the $\mathrm{C}$-terminal $\mathrm{CCG}$ domain as ligands of the [4Fe-4S] cluster [12]. Owing the absence of other conserved cysteine residues in $\mathrm{HdrB}$, cysteine residues of the $\mathrm{N}$-terminal CCG domain were suggested to provide the ligands to the zinc site. In SdhE, cysteine residues are completely restricted to the two CCG domains (ten cysteine residues in total). We therefore suggest that in analogy to $\mathrm{HdrB}$ the $\mathrm{C}$-terminal $\mathrm{CCG}$ domain provides the ligands for the $[4 \mathrm{Fe}-4 \mathrm{~S}]$ cluster, while cysteine residues of the $\mathrm{N}$-terminal $\mathrm{CCG}$ domain are engaged in zinc binding.

The comparison between SdhE and HdrB clearly indicates that the two proteins have different functions. A possible link between HDR and type E succinate dehydrogenase can be rationalized by the analysis of thiol:fumarate reductase, a methanogenic enzyme that couples the reduction of fumarate to succinate with the oxidation of coenzyme $\mathrm{M}$ and coenzyme $\mathrm{B}$ to the corresponding heterodisulfide [48, 49]. This soluble enzyme contains two catalytic modules, a fumarate reductase (or succinate dehydrogenase) module and a thiol dehydrogenase (or HDR) module with two CCG domains (Fig. 1). We suggest that the membrane-bound type E succinate dehydrogenase has evolved from a soluble thiol:fumarate reductase ancestor, which resulted in the conversion of the thiol dehydrogenase module with its catalytic [4Fe-4S] 
cluster into a membrane anchoring subunit. In this enzyme the catalytic $[4 \mathrm{Fe}-4 \mathrm{~S}]$ cluster of the $\mathrm{CCG}$ domain was no longer required and either was converted to a quinone reductase module or has adopted a structural role.

Acknowledgments This work was supported by the Max-PlanckGesellschaft, by the Deutsche Forschungsgemeinschaft, and by the Fonds der Chemischen Industrie. We wish to thank Rolf Thauer for generous support. We are also indebted to Thomas Prisner for giving us access to the pulse ENDOR spectrometer. We thank Antonio Pierik and Evert Duin for the help with EPR data analysis, Yasuhiro Takahashi for the gift of pRKISC, Arnulf Kletzin for the supply with genomic DNA of $S$. solataricus P2, Christian Schmidt for the cession of caldariella quinone, and Jürgen Koch and Jörg Kahnt for technical assistance. XAS research conducted in the R.A.S. laboratory is supported by the National Institutes of Health (GM042025). Portions of this research were carried out at the Stanford Synchrotron Radiation Laboratory, a national user facility operated by Stanford University on behalf of the US Department of Energy, Office of Basic Energy Sciences. The SSRL Structural Molecular Biology Program is supported by the Department of Energy, Office of Biological and Environmental Research, and by the National Institutes of Health, National Center for Research Resources, Biomedical Technology Program

Open Access This article is distributed under the terms of the Creative Commons Attribution Noncommercial License which permits any noncommercial use, distribution, and reproduction in any medium, provided the original author(s) and source are credited.

\section{References}

1. Hägerhäll C (1997) Biochim Biophys Acta 1320:107-141

2. Lancaster CR (2002) Biochim Biophys Acta 1553:1-6

3. Hederstedt L (1999) Science 284:1941-1942

4. Lancaster CR, Kröger A (2000) Biochim Biophys Acta 1459:422-431

5. Lemos RS, Fernandes AS, Pereira MM, Gomes CM, Teixeira M (2002) Biochim Biophys Acta 1553:158-170

6. Gomes CM, Lemos RS, Teixeira M, Kletzin A, Huber H, Stetter KO, Schaefer G, Anemueller S (1999) Biochim Biophys Acta 1411:134-141

7. Iwasaki T, Wakagi T, Oshima T (1995) J Biol Chem 270:3090230908

8. Janssen S, Schäfer G, Anemüller S, Moll R (1997) J Bacteriol 179:5560-5569

9. Lemos RS, Gomes CM, Teixeira M (2001) Biochem Biophys Res Commun 281:141-150

10. Bateman A, Coin L, Durbin R, Finn RD, Hollich V, GriffithsJones S, Khanna A, Marshall M, Moxon S, Sonnhammer EL, Studholme DJ, Yeats C, Eddy SR (2004) Nucleic Acids Res 32:D138-D141

11. Hedderich R, Klimmek O, Kröger A, Dirmeier R, Keller M, Stetter KO (1998) FEMS Microbiol Rev 22:353-381

12. Hamann N, Mander GJ, Shokes JE, Scott RA, Bennati M, Hedderich R (2007) Biochemistry 46:12875-12885

13. Iwasaki T, Kounosu A, Aoshima M, Ohmori D, Imai T, Urushiyama A, Cosper NJ, Scott RA (2002) J Biol Chem 277:3964239648

14. Li Z, Shokes JE, Kounosu A, Imai T, Iwasaki T, Scott RA (2003) Biochemistry 42:15003-15008
15. Takahashi Y, Nakamura M (1999) J Biochem (Tokyo) 126:917926

16. Nakamura M, Saeki K, Takahashi Y (1999) J Biochem (Tokyo) 126:10-18

17. Tong WH, Jameson GN, Huynh BH, Rouault TA (2003) Proc Natl Acad Sci USA 100:9762-9767

18. Beinert H, Albracht SP (1982) Biochim Biophys Acta 683:245-277

19. Bennati M, Weiden N, Dinse KP, Hedderich R (2004) J Am Chem Soc 126:8378-8379

20. Trautwein AX, Bill E, Bominaar E, Winckler H (1991) Ironcontaining proteins and related analogs-complementary Mössbauer, EPR and magnetic susceptibility studies. Springer, Heidelberg

21. Fish WW (1988) In: Riordan JF, Vallee BL (eds) Methods in Enzymology. Academic Press, New York, pp 357-364

22. Cline JD (1969) Limnol Oceanogr 14:454-458

23. Hunt JB, Neece SH, Ginsburg A (1985) Anal Biochem 146:150157

24. LeClerc GM, Grahame DA (1996) J Biol Chem 271:18725-18731

25. Smith PK, Krohn RI, Hermanson GT, Mallia AK, Gartner FH, Provenzano MD, Fujimoto EK, Goeke NM, Olson BJ, Klenk DC (1985) Anal Biochem 150:76-85

26. Werst MM, Kennedy MC, Houseman AL, Beinert H, Hoffman BM (1990) Biochemistry 29:10533-10540

27. Beinert H, Holm RH, Münck E (1997) Science 277:653-659

28. Dickson DPE (1984) In: Long GJ (ed) Mössbauer spectroscopy applied to inorganic chemistry. Plenum Press, New York, pp 339-384

29. Middleton P, Dickson DP, Johnson CE, Rush JD (1978) Eur J Biochem 88:135-141

30. Müh U, Buckel W, Bill E (1997) Eur J Biochem 248:380-384

31. Hoggins JT, Steinfink H (1976) Inorg Chem 15:1682-1685

32. Dunham WR, Bearden AJ, Salmeen IT, Palmer G, Sands RH, Ormejohn.Wh, Beinert H (1971) Biochim Biophys Acta 253:134

33. Walters EM, Garcia-Serres R, Jameson GN, Glauser DA, Bourquin F, Manieri W, Schurmann P, Johnson MK, Huynh BH (2005) J Am Chem Soc 127:9612-9624

34. Madadi-Kahkesh S, Duin EC, Heim S, Albracht SP, Johnson MK, Hedderich R (2001) Eur J Biochem 268:2566-2577

35. Mander GJ, Duin EC, Linder D, Stetter KO, Hedderich R (2002) Eur J Biochem 269:1895-1904

36. Pereira PM, Teixeira M, Xavier AV, Louro RO, Pereira IA (2006) Biochemistry 45:10359-10367

37. Pires RH, Venceslau SS, Morais F, Teixeira M, Xavier AV, Pereira IA (2006) Biochemistry 45:249-262

38. Ciurli S, Carrie M, Weigel JA, Carney MJ, Stack TDP, Papaefthymiou GC, Holm RH (1990) J Am Chem Soc 112:2654-2664

39. Duin EC, Bauer C, Jaun B, Hedderich R (2003) FEBS Lett 538:81-84

40. Duin EC, Madadi-Kahkesh S, Hedderich R, Clay MD, Johnson MK (2002) FEBS Lett 512:263-268

41. Kuo CF, McRee DE, Fisher CL, O'Handley SF, Cunningham RP, Tainer JA (1992) Science 258:434-440

42. Barthelme D, Scheele U, Dinkelaker S, Janoschka A, Macmillan F, Albers SV, Driessen AJ, Stagni MS, Bill E, Meyer-Klaucke W, Schunemann V, Tampe R (2007) J Biol Chem 282:14598-14607

43. Cecchini G, Sices H, Schroder I, Gunsalus RP (1995) J Bacteriol 177:4587-4592

44. Iverson TM, Luna-Chavez C, Cecchini G, Rees DC (1999) Science 284:1961-1966

45. Blobel G (1980) Proc Natl Acad Sci USA 77:1496-1500

46. Cole ST, Eiglmeier K, Ahmed S, Honore N, Elmes L, Anderson WF, Weiner JH (1988) J Bacteriol 170:2448-2456

47. Pellicer MT, Badia J, Aguilar J, Baldoma L (1996) J Bacteriol 178:2051-2059

48. Bobik TA, Wolfe RS (1989) J Biol Chem 264:18714-18718 
49. Heim S, Künkel A, Thauer RK, Hedderich R (1998) Eur J Biochem 253:292-299

50. Rius G, Lamotte B (1989) J Am Chem Soc 111:2464-2469

51. Kappl R, Ciurli S, Luchinat C, Hüttermann J (1999) J Am Chem Soc 121:1925-1935
52. Jameson GNL, Walters EM, Manieri W, Schurmann P, Johnson MK, Huynh BH (2003) J Am Chem Soc 125:1146-1147

53. Brown ID, Altermatt D (1985) Acta Crystallogr B 41:244-247 